\title{
Desmopressin for bed wetting: length of treatment, vasopressin secretion, and response
}

\author{
J H C Evans, S R Meadow
}

\begin{abstract}
Fifty five children with nocturnal enuresis referred to a hospital enuresis clinic entered a controlled trial to compare the efficacy of one month and three month courses of intranasal desmopressin (Desmospray). There was no significant difference in outcome between the two groups. Overall $36 \%$ improved by at least two dry nights/week during treatment, but only five children $(18 \%)$ in the one month group and three $(11 \%)$ in the three month group became completely dry and only one in each group remained dry after treatment.
\end{abstract}

To determine whether nocturnal polyuria was associated with a therapeutic response to desmopressin, the nocturnal urine volume, osmolality, and vasopressin concentration were measured in desmopressin responsive enuretics, desmopressin non-responders, and non-enuretic control children. There were no significant differences between the three groups.

A three month course of desmopressin is no more effective than a one month course. Although many children will improve during treatment, only a small number become dry and most will relapse when treatment is stopped.

In recent years, coincident with the introduction of a more convenient nasal spray (Desmospray, Ferring Pharmaceuticals), desmopressin has been prescribed frequently for children with nocturnal enuresis. Furthermore, as the United Kingdom product licence has recently been extended to allow up to three months of continuous use, it is likely that longer courses of treatment will be prescribed more often.

Although there have been studies comparing desmopressin with placebo ${ }^{1-3}$ they do not help the clinician decide on duration of treatment or selection of patients. This study, therefore, addressed two issues relating to the use of desmopressin for enuresis. The first issue was whether prolonging the duration of treatment from one month (the previous product licence limit) to three months improved either the short term or long term response. The second issue was whether nocturnal polyuria could be used to predict response to treatment. Previous studies have suggested that some children with nocturnal enuresis have lower nocturnal secretion of arginine vasopressin (AVP) than controls and consequently a larger nocturnal urine output. ${ }^{45}$ It is possible that these are the children most likely to benefit from the antidiuretic action of desmopressin, and thus it should be possible to identify those likely to respond favourably to desmopressin.

The aims of this controlled study were to compare the efficacy of a one month and a three month course of desmopressin, and to determine whether diminished AVP secretion and increased urine output at night before treatment were associated with a therapeutic outcome.

\section{Subjects and methods} THERAPEUTIC TRIAL

The trial was conducted in healthy children aged between 5 and 16 years who were wetting the bed at least two nights a week and who had been referred by general practitioners, community medical officers, urologists, or paediatricians to the enuresis clinic situated in a hospital paediatric outpatient department. Children were excluded from the trial if they were taking medications, such as salbutamol, that might cause a diuresis, or if they had had a urinary tract infection during the previous two weeks.

At the first visit a full history was taken, including inquiry about factors known to influence the outcome of treatment for enuresis such as housing problems (no indoor toilet, shared bedroom) and family difficulties (single parent, father in prison, marital discord, parental mental illness), ${ }^{6}$ while behavioural abnormalities were assessed by scoring a Rutter A2 questionnaire. ${ }^{7}$ A physical examination was performed, including a urine check for infection.

Bed wetting was documented by the children (aided by their parents) keeping a written record of wet and dry nights. During the trial no other treatment was allowed and the parents were asked not to restrict fluids or 'lift' their child to the toilet when they themselves went to bed.

A four week baseline observation period was undertaken after which the children were assigned to either one month or three months of treatment and then followed up for four weeks off all treatment. Children in the three month group were assessed after eight weeks of treatment; if no improvement was detected, alternative treatment was started. Desmopressin nasal spray (Desmospray) was prescribed initially in a dose of $20 \mu \mathrm{g}$ but increased to $40 \mu \mathrm{g}$ if there were any wet nights after the first three nights of use. The parent and child were asked to administer the spray in the half hour before retiring to bed. They received verbal and written instruction on how to administer the spray and this was demonstrated by the doctor using a placebo spray (supplied by Ferring Pharmaceuticals). 
Children were given desmopressin for one month or three months according to a system of quota allocation, ${ }^{8}$ which enabled the groups to be matched for Rutter A2 score, family or social problems, adverse housing, allergic rhinitis, age, severity, sex, the presence of diurnal wetting, and previous treatment for enuresis.

Therapeutic outcome was assessed by comparing the number of dry nights/week in the two groups before treatment, in the last two weeks of treatment, and in the last two weeks of follow up.

\section{AVP STUDY}

Urinary AVP excretion, urinary osmolality and nocturnal urine output were studied in children with enuresis and in non-enuretic control children. The enuretic children were studied before entering the therapeutic trial of desmopressin and were subsequently classified as either desmopressin responsive (improved by two or more dry nights/week during treatment) or treatment failures (no better or worse during treatment). Control subjects were enlisted from the healthy, non-enuretic siblings of children attending the general paediatric outpatient clinic with conditions other than enuresis.

Children were admitted to hospital for one night for assessment of nocturnal urine output and AVP excretion. After emptying their bladder before going to bed, urine was collected by waking the child every two hours to void until and including the urine voided immediately on rising in the morning.

Urine was collected into sterile containers and at the end of the collection the volume was measured and the sample well mixed before taking a $20 \mathrm{ml}$ aliquot which was stored at $-20^{\circ} \mathrm{C}$ for later analysis.

Urinary AVP concentrations were measured in duplicate by radioimmunoassay, using specific antiserum raised in rabbits, against AVP (Vasopressin Arginine Radioimmunoassay Kit, Diagnostic Systems Laboratories); the lower limit of detection of AVP was $10^{-3} \mathrm{pg} / \mathrm{l}$, and the coefficient of variation for the assay was between 5.6 and $10.5 \%$. Urinary creatinine concentration was measured by the Jaffé reaction, and urine osmolality was measured from the freezing point depression using an automated micro-osmometer (Hermann Roebling, Berling). Results were expressed as AVP:creatinine ratio.

The stability of AVP in urine was assessed by comparing the measured concentration of AVP in urine in a control sample that was stored at $-20^{\circ} \mathrm{C}$ immediately after voiding, a method of storage that does not affect the recovery of AVP from urine, ${ }^{9}$ with an aliquot of the same urine incubated at room temperature for 24 hours and with a further aliquot incubated at $37^{\circ} \mathrm{C}$ for 24 hours. The samples were each assayed five times in parallel.

\section{STATISTICAL METHODS}

Analysis of results was undertaken using the Statgraphics computer software package (STSC Inc).

In the therapeutic trial, comparison of the incidence of factors in the two groups was assessed by the $\chi^{2}$ test. The change in the mean number of dry nights between the start and end of treatment was compared between the two groups using the unpaired $t$ test with appropriately constructed confidence intervals; and the number of responders in the two groups compared using the $\chi^{2}$ test (for this purpose a 'response' was defined as an improvement of two or more dry nights/week and children withdrawn from the trial were considered nonresponders). In addition, the number of children who were completely dry in the two groups was compared using either the $\chi^{2}$ or Fisher's exact test.

In the urinary AVP study nocturnal urinary AVP:creatinine ratio, urine osmolality, and the nocturnal urine output were compared between three groups (controls, enuretic desmopressin responders, and enuretic treatment failures) using one way analysis of variance. The data were positively skewed and therefore log transformed for analysis, results being expressed in the original units using the geometric mean and the interquartile range.

The study received approval from the Leeds Eastern Health Authority ethics committee.

\section{Results}

Fifty five children were studied, 28 were assigned to one month of treatment and 27 to three months, using the quota allocation system. There were no significant differences between the two groups for the incidence of the characteristics shown in table $1\left(\chi^{2}<0.7,1 \mathrm{df}, \mathrm{p}>0.2\right.$ in each case). The median age was 10 years (range 5-16 in the one month group and $10 \cdot 8$ years (range 6-16) in the three month group.

Six children failed to complete the trial: two from the one month group and four in the three month group. One child developed chest pain and wheezing and stopped treatment on the advice of his general practitioner, five children failed to improve during treatment and the parents either stopped treatment early $(n=2)$, lifted the child during the night $(n=2)$, or failed to attend follow up appointments $(n=1)$. Twelve children in the three month group failed to improve after eight weeks of treatment and were given alternative therapy.

The figure demonstrates the number of dry nights/week in the two groups, before, during, and after treatment. In the one month group the median number of dry nights/week increased

Table 1 Characteristics of children allocated to either one month or three months of desmopressin, and the number showing these characteristics

\begin{tabular}{lll}
\hline & $\begin{array}{l}\text { I Month } \\
(n=28)\end{array}$ & $\begin{array}{l}3 \text { Months } \\
(n=27)\end{array}$ \\
\hline Previous treatment for enuresis & 19 & 19 \\
Male subject & 17 & 17 \\
Dry $\leqslant 2$ nights/week & 15 & 17 \\
Adverse family or social factors & 10 & 11 \\
Rutter A2 score $\geqslant 18$ & 9 & 8 \\
Age <8 years & 9 & 7 \\
Adverse housing & 9 & 6 \\
Diurnal symptoms & 8 & 7 \\
Allergic rhinitis & 1 & 1 \\
\hline
\end{tabular}




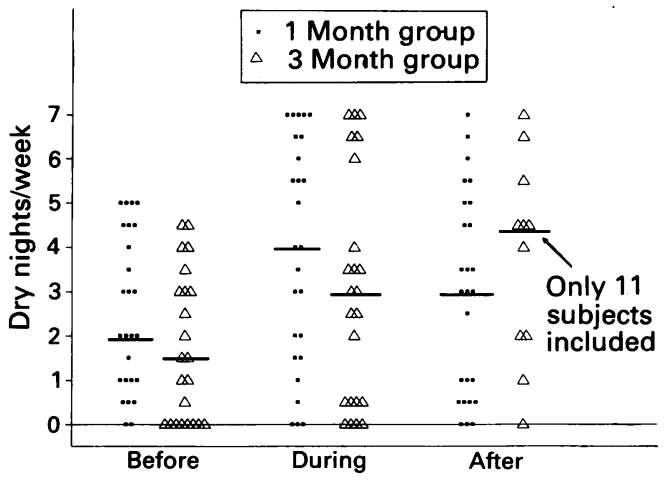

The number of drynights/week in children receiving treatment with either one month or three months of desmopressin. Median values represented by a bar.

from two to four with treatment, and declined to three nights/week after treatment. In the three months group the median values increased from 1.5 to three with treatment; follow up data were only available on a subgroup off 11 subjects who had responded to treatment and the median value for these subjects was $4 \cdot 5$ dry nights/week. The mean change (SD) in the number of dry nights/week with treatment was $+1.4(1.7)$ in the one month group and +1.3 in the three month group. The difference in the two group means was $0 \cdot 1$ nights/week $(95 \%$ confidence interval $-1 \cdot 1$ to $+0 \cdot 8, p=0 \cdot 75$ ).

There were no significant differences in the proportion of responders in the two groups either during treatment or after treatment (table 2). Overall 20 children (36\%) improved with treatment and $11(20 \%)$ remained so one month after treatment was completed. Only five children in the one month group (18\%) and three children in the three month group (11\%) became completely dry on treatment, and this difference was not significant (Fisher's exact test $p=0 \cdot 47)$. One in each group remained dry off treatment.

The measured concentration of AVP in urine incubated for 24 hours at room temperature $\left(22^{\circ} \mathrm{C}\right)$ or at $37^{\circ} \mathrm{C}$ was $96 \%$ and $87 \%$, respectively,

Table 2 The number of responders* in the one month and three month treatment groups

\begin{tabular}{llll}
\hline & $\begin{array}{l}1 \text { Month } \\
(n=28)\end{array}$ & $\begin{array}{l}3 \text { Months } \\
(n=27)\end{array}$ \\
\hline $\begin{array}{l}\text { During treatment } \\
\text { After treatment }\end{array}$ & 6 & 8 & $\begin{array}{l}\left(\chi^{2} 0 \cdot 5, p=0 \cdot 46\right) \\
\left(\chi^{2} 0 \cdot 07, p=1\right)\end{array}$
\end{tabular}

${ }^{*}$ Response defined as improvement by $\geqslant 2$ dry nights/week. of the control sample, which had been stored at $-20^{\circ} \mathrm{C}$.

Urine collections were obtained from eight enuretics with a median age of 12 years (range 7-18) who were subsequently classified as desmopressin responders, from 10 enuretics with a median age of 9 years (range 5-12) who were treatment failures, and from eight nonenuretic controls with median age 10.5 years (range 6-15). The urine volumes, osmolalities, and AVP concentrations in the three groups are shown in table 3 . There were no significant differences between groups for any of these parameters.

\section{Discussion}

Nocturnal enuresis is a common childhood problem, which in the majority of children can be managed successfully using behavioural treatments such as enuresis alarms. However, for some children drug treatments may be needed. When drugs are used it is logical to use the dosage and treatment regimen associated with maximum benefit. Desmopressin, an antidiuretic agent, is one of the few drugs effective in the treatment of nocturnal enuresis. Although most early studies used a dose of $10-20 \mu \mathrm{g},{ }^{3} 1011$ there is now good evidence that increasing the dose up to $40 \mu \mathrm{g}$ results in a higher response rate. ${ }^{5}$ Unfortunately, it also increases the expense of treatment. In order to justify the routine use of a three month course of desmopressin it would be necessary to demonstrate a substantially greater response than with shorter treatments. There are no published studies comparing different durations of treatment with desmopressin, though uncontrolled trials suggest that it remains effective when prescribed for months or even years ${ }^{12}$ and one study found no difference in the number of dry nights in the first and last two weeks of treatment. ${ }^{2}$

Our study did not demonstrate any difference between one month and three months of treatment in the proportion of children dry or improved, either during treatment or when reviewed four weeks after the end of treatment. Overall, $36 \%$ appeared to benefit from treatment with $15 \%$ dry and a further $21 \%$ improved, while off treatment $4 \%$ (two patients) were dry and a further $16 \%$ improved. Direct comparison with previous publications is difficult because of the variety of dosages used, the variety of populations and age ranges studied and because of the different methods chosen to describe outcome. Controlled trials have shown that

Table 3 The urinary data of enuretics who responded or failed to respond to desmopressin, and in non-enuretic controls

\begin{tabular}{|c|c|c|c|c|}
\hline & $\begin{array}{l}\text { Responders } \\
(n=8)\end{array}$ & $\begin{array}{l}\text { Non-responders } \\
(n=10)\end{array}$ & $\begin{array}{l}\text { Controls } \\
(n=8)\end{array}$ & \\
\hline $\begin{array}{l}\text { Nocturnal urine volume }(\mathrm{ml}) \\
\text { Geometric mean } \\
\text { Range } \\
\text { Nocturnal urinary osmolality }(\mathrm{mmol} / \mathrm{kg})\end{array}$ & $\begin{array}{l}345 \\
193-620\end{array}$ & $\begin{array}{l}265 \\
140-800\end{array}$ & 221 & $\begin{array}{l}F \text { ratio } 1 \cdot 5 \\
p=0.23\end{array}$ \\
\hline $\begin{array}{l}\text { Geometric mean } \\
\text { Range }\end{array}$ & $\begin{array}{l}506 \\
285-1053\end{array}$ & $\begin{array}{l}578 \\
243-1113\end{array}$ & $\begin{array}{l}703 \\
348-1069\end{array}$ & $\begin{array}{l}F \text { ratio } 1.2 \\
\mathrm{p}=0.32\end{array}$ \\
\hline $\begin{array}{l}\text { Nocturnal urinary AVP concentration (pg/mmol creatinine) } \\
\text { Geometric mean } \\
\text { Range }\end{array}$ & $\begin{array}{l}0.9 \\
0.2-3 \cdot 9\end{array}$ & $\begin{array}{l}2 \cdot 8 \\
0 \cdot 7-10 \cdot 8\end{array}$ & $\begin{array}{l}2 \cdot 6 \\
0 \cdot 5-16 \cdot 8\end{array}$ & $\begin{array}{l}F \text { ratio } 2 \cdot 0 \\
p=0 \cdot 15\end{array}$ \\
\hline
\end{tabular}


between $12 \%$ and $70 \%$ become dry during treatment ${ }^{13511}$ while $41 \%-88 \%$ are perceived to improve significantly. ${ }^{1310}$ The proportion who are dry after treatment stops varies between 0 and 31\%. ${ }^{1313}$ By comparison, our response rates are low. One possible explanation for this is the high proportion of children with refractory enuresis $(69 \%)$, although in many cases the initial treatment was only a short trial of imipramine with little or no supervision. Dimson in a study of refractory enuretics found similarly poor results with $12 \%$ dry, $41 \%$ improved, and $0 \%$ dry after treatment. ${ }^{3}$

Nocturnal polyuria has long been considered as a possible contributory factor in the pathogenesis of enuresis. ${ }^{14}$ It is known that healthy adults and children exhibit an appreciable diurnal variation in urine output, ${ }^{5} 15$ which diminishes during the night irrespective of whether the individual sleeps or refrains from drinking during the night, and that the probable explanation for this is the presence of a diurnal variation of AVP release with an increase in plasma AVP concentration during the night. ${ }^{5} 16$ Early studies of night time urine production have produced conflicting results in children, Poulton and Hinden found that the majority of enuretic children did have nocturnal polyuria, but a detailed study by Vulliamy showed similar urine outputs in enuretic children and non-enuretic controls (with the physiological diurnal variation present in both groups). ${ }^{14} 17$ Recent studies of children aged 11-17 years with and without enuresis, receiving a strictly controlled fluid intake, have shown a significant blunting of the diurnal rhythm in plasma AVP, with either very little or no increase in the night time concentration in the enuretic children, and that this is associated with a loss of the diurnal rhythm of urine output, with enuretics not exhibiting the expected reduction in nocturnal urine production. 45

It is tempting to speculate that those children with nocturnal polyuria secondary to AVP deficiency are the ones most likely to benefit from desmopressin. Dimson found that children who concentrated their urine (increasing the early morning urinary osmolality to $>1000$ $\mathrm{mmol} / \mathrm{kg}$ ) after desmopressin had the best clinical response, but also showed that those who already had a high early morning urinary osmolality responded well. ${ }^{3}$

Our study of nocturnal urine output, urinary vasopressin concentration, and urine osmolality did not demonstrate a significant difference between control children, enuretics who did not respond to desmopressin, and enuretics who did respond to desmopressin. There was, however, a trend towards the desmopressin responsive enuretics having lower AVP concentrations and larger volumes of dilute urine at night, with the (geometric) mean urine volume highest in the responders and lowest in the controls, while the AVP concentrations were lowest in the responders, intermediate in the non-responders, and highest in controls. This trend was small compared with the wide range of values seen in each group.

We elected to study urinary AVP concentrations (rather than plasma) for a number of reasons: it avoids the need for venepuncture; urinary AVP concentrations have been shown to have a consistent relationship with plasma concentrations in children ${ }^{18}$; and as plasma AVP has a half life of only a few minutes, urine collection may provide a more reliable assessment of AVP secretion over a period of time than intermittent venous sampling which may miss significant peaks.

There are a number of methodological factors that might explain the contrasting results between our study and that of Rittig et al. ${ }^{5}$ Firstly, Rittig et al studied only older children whereas we included children as young as 6 years; it is possible that the diurnal variations in AVP are less well developed in younger children. Secondly, Rittig et al studied children under conditions of fluid restriction, which may allow identification of minor abnormalities of AVP production that are not apparent when children receive a normal fluid intake and which, more importantly, do not result in a significant change in urine output at night.

We conclude that, although there may be some abnormality in the diurnal rhythm of AVP release in children with nocturnal enuresis, when they are allowed a free fluid intake it does not result in a significant increase in night time urine production nor is it a major determinant of therapeutic response to desmopressin.

Desmopressin is a useful treatment for some children with nocturnal enuresis. Although it produces some benefit for many children, few of those children become completely dry, and most relapse once the treatment is stopped. A three month course of treatment does not increase the response rate or decrease the relapse rate when compared with a one month course in children referred to the hospital outpatient clinic. Measurement of nocturnal urine volume, osmolality, and AVP concentration does not identify clearly those who will respond to desmopressin. As improvement is seen early in treatment, responders can be identified by a short therapeutic trial and continued use reserved for those who are benefiting from treatment. This work was supported by Ferring Pharmaceuticals. We are
grateful for the careful laboratory work of John Wheeldon and grateful for the careful laboratory
for the assistance of Mandy Jones.

1 Birkasova M, Birkas O, Flynn MJ, Cort JH. Desmopressin in the management of nocturnal enuresis in children: double-blind study. Pediatrics 1978;62:970-4

2 Post EM, Richman RA, Blackett PR, Duncan KP, Miller K. Desmopressin response of enuretic children: effects of age Desmopressin response of enuretic children: effects of age
and frequency of enuresis. Am $\mathcal{F}$ Dis Child 1983;137:962-3.

3 Dimson SB. DDAVP and urine osmolality in refractory enuresis. Arch Dis Child 1986;61:1104-7.

4 Norgaard JP, Pederson EB, Djurhuus JC. Diurnal antidiuretic hormone levels in enuretics. $\mathcal{F}$ Urol 1985;134:1029-31.

5 Rittig S, Knudsen UB, Norgaard JP, et al. Abnormal diurnal rhythm of plasma vasopressin and urinary output in patients with enuresis. Am J Physiol 1989;256:664-71.

6 Dische S, Yule W, Corbett J, Hand D. Childhood nocturna enuresis: factors associated with outcome of treatment with an enuresis alarm. Dev Med Child Neurol 1983;25:67-80.

7 Rutter M, Tizzard J, Whitmore K. Education health and behaviour. London: Longmans, 1970.

8 McGuire R. Quota allocation. I Psychosom Res 1968;12 168-9.

9. Wiriyathian S, Rosenfeld CR, Arant JR, Porter JC, Faucher DJ, Engle WD. Urinary arginine vasopressin: pattern of excretion in the neonatal period. Pediatr Res 1986;10: $103-8$.

10 Tuvemo T. DDAVP in childhood nocturnal enuresis. Acta Paediatr Scand 1978;67:753-5. 
11 Aladjem M, Wohl R, Boichis H, Orda S, Lotan D, Freedman $\mathrm{S}$. Desmopressin in nocturnal enuresis. Arch Dis Child 1982;57:137-40.

12 Delaere KP, Strijobs WE. Antidiuretic approach with DDAVP for nocturnal enuresis. Acta Urol Belg 1986;54: 464-70.

13 Ramsden PD, Hindmarsh JR, Price DA, Yeates WK Bowditch JD. DDAVP for adult enuresis-a preliminary report. Br $\mathcal{F}$ Urol 1982;54:256-8.

14 Poulton EM, Hinden E. The classification of enuresis. Arch Dis Child 1953;28:392-7.
15 Mills JN. Diurnal rhythm in urine flow. $\mathcal{f}$ Physiol 1951;113: 528-36.

16 George CP, Messeleri FH, Genest J, et al. Diurnal variation of plasma vasopressin in man. $\mathcal{J}$ Clin Endocrinol Metab 1975;41:332-7.

17 Vulliamy D. The day and night output of urine in enuresis. Arch Dis Child 1956;31:439-43.

18 Stern P, La Rochelle FT. Similar relationship between plasma and urinary vasopressin in infants and adults. Pediatr Res 1982;16:329A.

\section{Water intoxication}

'For every action there is an equal and opposite reaction'. Twenty years ago severe hypernatraemic dehydration was common but after the introduction of low solute milks in the mid-1970s it became rare. Now there is concern in the United States about an apparent increase in severe acute hyponatraemia in babies of poor inner city families some of which may be attributable to the introduction of the low solute milks. ${ }^{1}$ As hyponatraemia is much less likely than hypernatraemia to give rise to serious sequelae the exchange seems to be a fair one though the problem of hyponatraemia needs to be tackled by public education.

A report from the Children's Hospital of St Louis, Missouri (James P Keating and colleagues, American Fournal of Diseases of Children 1991;145:985-90) gives details of 31 infants with water intoxication seen between 1975 and 1990, 22 of whom had been seen in the last three years. Quite why this sudden increase occurred in 1988 is not well explained. Fourteen of the 31 babies were girls and their ages ranged from 1 to 10 months. They all presented to hospital after the sudden onset of apnoea or convulsions. Although these are attributed to cerebral oedema, bulging of the fontanelle was 'notably absent' and neither plain radiographs of the skull nor computed tomograms showed evidence of raised intracranial pressure or cerebral oedema. All but four of the babies had a serum sodium of less than $120 \mathrm{mmol} / \mathrm{l}$ at the time of admission (range 111-127 mmol/l). They had been given excess water, usually as tap water but sometimes as dilute formula, over a period of two to eight hours at a rate of about $7 \cdot 51 / \mathrm{m}^{2}$ of body surface area/day (around $300 \mathrm{ml} / \mathrm{kg}$ day) shortly before admission. They came from an inner city area of very high social deprivation. Sixteen had been given water because they had 'run out of formula', four because of diarrhoea, and the remaining 11 for a variety of reasons including irritability, apparent thirst, and hot weather. They were treated by either rapid infusion of hypertonic saline or slow infusion of an isotonic solution and all recovered completely. Dr Finberg in his editorial advises against the use of hypertonic solutions. ${ }^{1}$

Water intoxication does not seem to have been a problem in Britain so far. There have been two reports in this journal, from Israel $^{2}$ and Thailand. ${ }^{3}$ The reasons behind the American outbreak are unclear. Why should parents suddenly begin to poison their babies with water? There must be something we don't know about. So often we seem to prepare ourselves for the eastward spread of an American problem and it doesn't happen but a little prophylactic education about the potential danger of excessive water administration might not be a bad thing.

Finberg $\mathrm{L}$. Water intoxication: a prevalent problem in the inner city [Editorial]. $A m \mathcal{J}$ Dis Child 1991;145:981-2.

2 Etzioni A, Benderley A, Levi Y. Water intoxication by the oral route in an infant. Arch Dis Child 1979;54:551-3.

3 Vanapruks V, Prapaitrakul K. Water intoxication and hyponatraemic convulsions in neonates. Arch Dis Child 1989;64:734-5. 